\title{
Examination of Heart Failure as a Predictor of Driving Cessation
}

\author{
Bernadette A. Fausto, MS ${ }^{a}$, Adrian N.S. Badana, MPHa, Olivia M. Valdes, BA ${ }^{b}$, Ponrathi \\ Athilingam, $\mathbf{P h D}^{\mathrm{c}}$, and Jerri D. Edwards, $\mathrm{PhD}^{\mathrm{d},{ }^{*}}$ \\ aSchool of Aging Studies, University of South Florida, 4202 E. Fowler Avenue, Tampa, FL 33620, \\ United States \\ bDepartment of Psychology, Florida Atlantic University, 3200 College Avenue, Fort Lauderdale, FL \\ 33314, United States \\ ${ }^{\circ}$ College of Nursing, University of South Florida, 12901 Bruce B Downs Blvd, MDC 22, Tampa, FL \\ 33612, United States \\ ${ }^{\mathrm{d}}$ Department of Psychiatry and Behavioral Neurosciences, University of South Florida, $3515 \mathrm{E}$. \\ Fletcher Ave., MDC 14, Tampa, FL 33613
}

\begin{abstract}
Cognitive dysfunction is a predictor of driving cessation in older adults and a common sequela of heart failure (HF). Although HF has been associated with an increased risk of driving cessation, the independent relationship between $\mathrm{HF}$ and driving cessation after cognitive function is considered remains to be established. The objective of these analyses is to examine $\mathrm{HF}$ as an independent predictor of driving cessation across three years among a cohort of older drivers in the United States. Analyses included 850 older adults who completed sensory, cognitive, and physical measures at baseline and mobility and health measures at a three-year follow-up. Cox regression was used to examine the effects of HF, stroke, vision, cognition, and physical function as predictors of incident driving cessation over three years. Participants with HF were over three times more likely to cease driving, $H R=3.19,95 \% \mathrm{CI}$ [1.27, 8.02], $p=.014$. However, HF was no longer a significant predictor of driving cessation when cognitive performance was considered, $H R$ $=1.70,95 \% \mathrm{CI}[0.67,4.30], p=.262$. These findings suggest that the risk of driving cessation may be a consequence of the cognitive dysfunction associated with HF, rather than from HF itself. Cognitive training should be investigated among persons with HF to potentially prolong driving mobility.
\end{abstract}

\section{Keywords}

cognitive function; driving; heart failure

\footnotetext{
*Corresponding author. Tel. (813) 974-6703, Fax: (813) 974-3236.

Publisher's Disclaimer: This is a PDF file of an unedited manuscript that has been accepted for publication. As a service to our customers we are providing this early version of the manuscript. The manuscript will undergo copyediting, typesetting, and review of the resulting proof before it is published in its final citable form. Please note that during the production process errors may be discovered which could affect the content, and all legal disclaimers that apply to the journal pertain.
} 


\section{Introduction}

Heart failure (HF) is a chronic, progressive disease affecting 6.5 million people in the United States (Benjamin et al., 2017). HF arises as a result of an abnormality in the cardiac structure, function, rhythm, or conduction (Kemp and Conte, 2012) and becomes increasingly prevalent with age (Benjamin et al., 2017). Cardiac (e.g., hypertension, diabetes mellitus, anemia) and non-cardiac (osteoporosis, asthma) comorbidity is prevalent in $\mathrm{HF}$ (Madvig et al., 2011; van Deursen et al., 2014) with approximately $60 \%$ of individuals with HF having three or more medical comorbidities accompanied by functional and cognitive impairment (Murad et al., 2015). Among older adults, HF may be a risk factor for driving cessation (Sims et al., 2011), which can lead to decreased quality of life (Chihuri et al., 2016). One in four patients with HF have cognitive impairment affecting three or more domains of cognition (Pressler et al., 2010). However, whether HF is an independent predictor of driving cessation when cognitive function is considered remains to be established. The current study seeks to examine HF as a predictor of driving cessation among older adults and to investigate whether HF remains a significant risk factor for driving cessation after accounting for cognitive function and other known risk factors.

It is important to examine risk factors for driving cessation as it has adverse implications for individuals' health and well-being (Edwards et al., 2009b; Marottoli et al., 2000). For example, driving cessation is associated with higher risk of nursing home admissions (Freeman et al., 2006). Additionally, Edwards and colleagues (2009b) found that older adults who discontinued driving experienced greater declines in health over time.

The compromised cognitive function associated with HF may potentially lead to changes in driving habits. Although previous studies have identified HF as a risk factor for driving cessation (Sims et al., 2011), the relation between HF and driving cessation may be due to the cognitive impairments associated with both phenomena (Alosco et al., 2013; Alosco et al., 2014). Cognitive dysfunction, especially in domains of executive function, attention, and speed of processing are common in individuals suffering from HF (Leto and Feola, 2014). A study by Gure and colleagues (2012) indicated that approximately $40 \%$ of patients aged 65 and older diagnosed with HF are cognitively impaired. One recent study showed that older adults with HF performed more poorly on speed of processing for visual attention tasks as measured by the Useful Field of View Test (UFOV ${ }^{\circledR}$ ) than those without HF (Alwerdt et al., 2013). The UFOV is a significant predictor of driving outcomes including driving cessation (Ackerman et al., 2008; Edwards et al., 2010; Edwards et al., 2008; Emerson et al., 2012). Thus, it may be that the cognitive impairment associated with HF leads to driving cessation.

Several other factors besides cognition are indicative of risk for driving cessation. In addition to the UFOV, poor cognitive performance on other measures of speed of processing, including the Digit Symbol Substitution Test (Edwards et al., 2008) and the Trail Making Test-Part A (Emerson et al., 2012) are predictive of driving cessation. Memory, as indicated by the Benton Visual Retention Test (Emerson et al., 2012), and everyday reasoning, as indicated by the Everyday Problems Test (Ackerman et al., 2008), have also been identified as predictors of driving cessation. Poor physical functioning, as measured by the Turn 360 test, the short form health survey (SF-36; Ackerman et al., 2008; Edwards et al., 2008), and 
difficulty walking half a mile (Sims et al., 2011) have also been associated with driving cessation. In addition to poor cognitive and physical functioning, older age (Ackerman et al., 2008; Edwards et al., 2010; Edwards et al., 2008; Emerson et al., 2012; Sims et al., 2011), poorer vision (Emerson et al., 2012; Sims et al., 2011), lower number of days driven per week (Ackerman et al., 2008; Edwards et al., 2010), and stroke (Sims et al., 2011), increase risk for driving cessation.

Although HF was shown to be a risk factor for driving cessation (Sims et al., 2011), no prior studies have examined if this association can be explained by the concomitant cognitive impairments (Alosco et al., 2013; Alosco et al., 2014; Alwerdt et al., 2013). Thus, whether $\mathrm{HF}$ is an independent predictor of driving cessation remains unclear. The purpose of these analyses was to examine $\mathrm{HF}$ as a predictor of driving cessation across three years among a cohort of older drivers in the United States. We hypothesized that HF would not significantly predict driving cessation when considering cognitive function.

\section{Method}

\subsection{Participants}

Participants were drawn from the Staying Keen in Later Life (SKILL) and the Advanced Cognitive Training for Independent and Vital Elderly (ACTIVE) studies. Previous research has used combined data from the SKILL and ACTIVE studies as the inclusion criteria, measures, and procedures overlapped (Edwards et al., 2009a). To be eligible for inclusion in the present analyses, participants from both studies were current drivers at baseline, did not receive any cognitive training, and successfully completed a three-year follow-up. The SKILL and ACTIVE samples are described respectively below.

The SKILL study involved community dwelling adults who were recruited from Alabama and Kentucky via mass mailings. Inclusion criteria for SKILL were as follows: 60 years of age or older, a literacy level of fifth grade or above, adequate vision (far visual acuity 20/80 or better), and a score of 23 or above on the Mini Mental State Exam (MMSE), as detailed elsewhere (Edwards et al., 2005b). Participants from the SKILL study who completed the baseline phase, defined themselves as current drivers, did not receive cognitive training, and were successfully contacted for follow-up three years later were eligible for inclusion in these secondary data analyses, resulting in 434 participants from SKILL.

The ACTIVE study involved community dwelling adults who were recruited from six metropolitan areas throughout the United States. Inclusion criteria for ACTIVE were as follows: 65 years of age or older, adequate vision (far visual acuity 20/50 or better), no functional impairments, and a score of 23 or above on the MMSE. Inclusion criteria for the ACTIVE study are detailed elsewhere (Jobe et al., 2001). In the ACTIVE study, 698 participants were randomized to the control condition, and did not receive cognitive training. Of these participants, 443 were baseline drivers who completed the three-year follow up and were included in analyses.

The combined SKILL and ACTIVE analytic sample $(N=877)$ consisted of adults ranging in age between 63 to 91 years. Participant demographics by HF status are displayed in Table 1 . 


\subsection{Measures}

The MMSE (Folstein et al., 1975) was administered in order to reduce the likelihood of including participants with dementia. Possible scores range from 0 to 30 with higher scores indicating better performance. Only those scoring 23 or above were included in analyses. The test-retest reliability of this measure ranges from .38 to .99 (Tombaugh and McIntyre, 1992).

The touch, PC, four subtest version of the Useful Field of View Test (UFOV ${ }^{\circledR}$ ) was used to assess cognitive speed of processing for visual attention tasks (Edwards et al., 2006). The UFOV is composed of four subtests, each progressively more difficult. For each subtest, the display-duration threshold value for $75 \%$ correct performance was measured, which varied from 16.67 to $500 \mathrm{~ms}$. The first subtest requires the participant to identify a central target (car or truck). The second subtest includes the central target identification task with a simultaneous peripheral target localization. The peripheral target is presented at one of eight radial locations simultaneously with the presentation of the central target. The third subtest comprises the central target identification task and simultaneous peripheral localization task with added visual distractors surrounding the peripheral target. In the fourth subtest, participants are also required to simultaneously locate a peripheral target, but the central task involves determining whether two items presented in the center are the same or different (car/car, truck/truck or car/truck). The sum of the four subtest scores was used in analyses, with possible scores ranging from 66.68 to $2000 \mathrm{~ms}$. The test-retest reliability of this measure ranges from .74-.81 (Edwards et al., 2005a).

The Wechsler Adult Intelligence Scale-Revised Digit Symbol Substitution Test was included as a measure of cognitive speed of processing (Wechsler, 1981). The test consists of a key with numbers (digits) ranging from 1 and 9 each paired with a corresponding unique symbol. Participants are also given a grid of empty squares with numbers above each square and are given 90 seconds to fill in the empty squares with the correct symbol that corresponds with the number provided in the key. The total correct substitutions made were recorded. The reliability of this measure has been reported as .82 (Wechsler, 1981).

Far visual acuity was measured via an early treatment of diabetic retinopathy letter chart using standard procedures (Jobe et al., 2001). Scores were assigned on a range from 0 to 90 , depending on the number of letters that were correctly discriminated with a score of 90 equivalent to a Snellen score of 20/16. A higher number reflected better far visual acuity.

The Turn 360 test was used to assess balance (Steinhagen-Thiessen and Borchelt, 1999). Participants were asked to stand and turn in one full circle. The number of steps required to make a full turn was used with fewer steps signifying better balance. Participants completed two turns and the average number of steps taken across two attempts was used for the analyses. The reliability of this measure has been reported as .92 (Tager et al., 1998).

Participants reported whether a doctor or nurse had informed them of any of the following existing health conditions: arthritis, asthma/chronic bronchitis/emphysema, cancer (other than skin cancer), chronic skin problems, diabetes, heart failure, high cholesterol, hypertension, mood problems, multiple sclerosis, osteoporosis, Parkinson's disease, memory 
impairment, and/or strokes (including transient ischemic attacks) using a previously validated survey (Jobe et al., 2001).

Driving behaviors were assessed via the Driving Habits Questionnaire (Owsley et al., 1999). The first question asked participants whether they were current drivers. This was defined as "someone who has driven a car within the last 12 months and someone who would drive a car today if they needed to." All other questions pertained to current drivers and asked about driving frequency, driving difficulty, and driving space. Current driver status at baseline and three-year follow-up and driving frequency at baseline (defined as the number of days driven per week) were used in analyses. This questionnaire has demonstrated good test-retest reliability for current driver status, $r=.73$ and driving frequency, $r=.83$ (Owsley et al., 1999).

\subsection{Procedure}

In the SKILL and ACTIVE studies, participants completed testing over 2-3 sessions from 1.5 to 3 hours in duration and were allowed to take breaks at any time to avoid fatigue.

These secondary data analyses were conducted using the combined prospective cohort data from the SKILL and ACTIVE studies. Time to driving cessation was calculated as the number of months between baseline assessment and the reported date of driving cessation. For those who did not cease driving, time was right-censored at death or three-year followup, whichever first occurred.

HF status was assessed using data from a yes/no item concerning whether a doctor or nurse ever diagnosed the individual with HF from the self-report health questionnaire. Responses to this item were collapsed across time points between baseline and three-year follow-up, yielding two groups: Those who were never diagnosed with HF from baseline to three-year follow-up and those diagnosed with HF at any time point between baseline to three-year follow-up.

\subsection{Analyses}

Statistical analyses were performed using the Statistical Package for Social Sciences software, version 23.0 (SPSS Inc., Chicago, IL). To aid in interpretation and adjust for variable scaling, UFOV, DSS, and Turn 360 performances were converted into $z$-scores with all outliers exceeding \pm 2.5 standard deviations assigned a $z$-score of \pm 2.5 (Wood et al., 2005). $Z$-scores for UFOV, DSS and Turn 360 were used for analyses.

The analyses included Chi-square tests of independence to determine if there were differences in the HF groups by race or sex. A phi correlation was conducted to examine the degree of association between two binary variables, HF and driving cessation. Cox regressions were used to examine the probability of driving cessation across baseline to three-years. We explored three separate models with HF entered in the first step, UFOV and DSS entered in the second step, and other known predictors of driving cessation entered in the third step (Turn 360, age, far visual acuity, days driven per week, and stroke). HF was entered in the first step on the basis of previous literature citing HF as a significant predictor of driving cessation (Edwards et al., 2008; Sims et al., 2011). Next, to identify whether HF 
remained significant after considering cognitive function, UFOV and DSS were entered as poorer performance on these measures is associated with driving cessation (Ackerman et al., 2008). Well-documented predictors of driving cessation were entered in the last model including poor physical functioning, as measured by the Turn 360 test (Ackerman et al., 2008; Edwards et al., 2008), older age (Ackerman et al., 2008; Edwards et al., 2010; Edwards et al., 2008; Emerson et al., 2012; Sims et al., 2011), poorer vision (Emerson et al., 2012; Sims et al., 2011), average number of days driven per week (Ackerman et al., 2008; Edwards et al., 2010), and stroke (Sims et al., 2011).

\section{Results}

Of the 877 total SKILL and ACTIVE combined participants, 27 participants were excluded from analyses due to missing data. Eleven participants were missing Turn 360 scores, seven participants were missing baseline UFOV composite scores, three participants were missing data on driving status at three-year follow-up, three participants were missing race, one participant was missing baseline days driven per week, one participant was missing a DSS score, and one participant was missing data on stroke. Less than $1 \%$ of data points were missing. Missingness (missing one or more data points versus no missing data) did not differ by HF status, $\chi^{2}(1,875)=0.007, p=.935$ or MMSE scores, $t(875)=-2.567, p=.010, d=$ 0.17. Analyses included 850 participants. Of these participants, 34 stopped driving by the three-year follow-up. Descriptive statistics of these participants by HF status are reported in Table 1.

First, Chi-square tests of independence were calculated to determine if there were differences between HF groups in race or sex. Results indicated that there was no relation between HF and race, $\chi^{2}(1,848)=0.077, p=.781$, or HF and sex, $\chi^{2}(1,848)=0.023, p=$. 879.

Next, a phi correlation coefficient was calculated to examine the association between HF and driving cessation. Results indicated that there was a significant association between $\mathrm{HF}$ and driving cessation, $\Phi_{(848)}=-.160, p<.001$. Participants who had HF were more likely to cease driving compared to participants who did not have HF. Whereas only $3.4 \%$ of those without HF stopped driving, $20.7 \%$ of those with HF stopped driving in three years.

Cox regression survival analyses were used to determine if HF was a significant predictor of driving cessation across three years and, if so, whether HF remained significant after taking into account measures of cognition entered second, as well as physical functioning, age, far visual acuity, and baseline driving frequency entered last. Results indicated that HF was a significant predictor of driving cessation in model one. Individuals who were diagnosed with HF were three times more likely to cease driving. After adding UFOV and DSS performance in model two, HF was no longer a significant predictor of driving cessation, but UFOV emerged as a significant predictor (see Table 2). Individuals with poorer baseline UFOV performance were nearly three times more likely to cease driving. After adding other known predictors of driving cessation in model three, UFOV remained a significant predictor of driving cessation and days driven per week also emerged as a significant predictor. See Table 2 for statistics. 


\section{Discussion}

While previous research has shown that HF is a predictor of driving cessation (Sims et al., 2011), the effect of a HF diagnosis after considering cognitive function had not been previously examined. In the present study, we found that HF alone was a significant predictor of driving cessation. However, after considering cognitive function, HF was no longer a significant predictor of driving cessation across a three-year time period. Thus, the risk of driving cessation may be a consequence of the cognitive dysfunction associated with HF, rather than HF itself.

Poor speed of processing for visual attention tasks, as measured by the UFOV, is a known risk factor for driving cessation above and beyond physical health (Edwards et al., 2008). Prior research indicated that UFOV performance declines may precede a HF diagnosis (Alwerdt et al., 2013). Thus, although previous studies have identified HF diagnosis as a risk factor of driving cessation, the higher prevalence of cognitive decline, as measured by UFOV in particular, among those with HF may confer greater risk for driving cessation.

In addition, the present study found lower baseline driving frequency as a significant risk factor for driving cessation across a three-year period. Prior research indicates that individuals who drive less at baseline are more likely to cease driving (Edwards et al., 2008). In contrast, previously identified risk factors including age, DSS performance, and far visual acuity were not indicators of driving cessation in these analyses. One explanation for the lack of significant results for age, DSS and far visual acuity is that UFOV places both cognitive and sensory demands on the individual, regardless of age. Given the similarly multifactorial nature of driving, UFOV may be a stronger predictor of driving cessation than age, DSS, or visual acuity (Ackerman et al., 2008).

In the present study, HF status was self-reported, which is a limitation. Further, a small number of individuals self-reported HF $(3 \%, n=29)$. According to the Centers for Medicare and Medicaid Services (2017) claims data, HF prevalence is $14 \%$. Our study involved community-dwelling healthy older adults, therefore HF prevalence is lower than what would be observed in a clinical population. Individuals in moderate to severe HF stages are less likely to participate in community-based research; therefore, the effect may be underestimated. Whether the participants with HF used a pacemaker/defibrillator was not collected. Although prior research has not found HF comorbidities to be independent predictors of driving cessation, with the exception of stroke, it is possible that other comorbidities not examined in this study, such as kidney disease, contribute to driving cessation. Another limitation is that the timing of HF diagnosis is unknown. However, prior research indicated that UFOV difficulties precede HF diagnosis, which lessens concerns (Alwerdt et al., 2013). Despite these limitations, the data highlight the importance of the role of cognitive dysfunction in HF.

The ability to drive is a major contributor to quality of life and independence (Almeida et al., 2012; Emerson et al., 2012; Lossnitzer et al., 2013). Knowledge of negative social and health consequences due to medical conditions may facilitate early treatment as well as planning for driving cessation. Fortunately, cognitive training, specifically speed of 
processing training, improves on-road driving performance (Roenker et al., 2003); prolongs driving mobility (Edwards et al., 2009c); reduces rates of driving cessation (Edwards et al., 2009a); and reduces at-fault motor vehicle crash involvement (Ball et al., 2010). This intervention has shown potential efficacy in HF as well (Ellis et al., 2014).

\section{Conclusions}

Our findings suggest that patients with HF are at an increased risk for driving cessation particularly due to cognitive difficulties (i.e., UFOV). Future research should investigate heart failure diagnosis ascertained through medical records as a predictor of driving cessation to determine if similar results emerge. Although patients with HF have increased risk of cognitive decline compared to the general population, cognitive assessment or training is not recommended by the current HF guidelines, which should be addressed. Preliminary analyses indicate that cognitive speed of processing training may improve UFOV performance among individuals with HF (Ellis et al., 2014). Ongoing work is examining the potential effects of cognitive training in patients with HF.

Driving cessation may impair older adults' mobility, social function, and can potentially result in loneliness and depression (Chihuri et al., 2016). Driving cessation may even accelerate health declines and thus increase mortality (Edwards et al., 2009b; Edwards et al., 2009d). Multiple studies have demonstrated that UFOV training prolongs safe driving mobility among older adults (Edwards et al., 2009c; Roenker et al., 2003). Thus, cognitive training may be a viable option to sustain driving mobility and well-being among individuals with HF who may consequently be at an increased risk of cognitive impairment. Cognitive training can enhance driving performance for older adults (Roenker et al., 2003). Future research should further examine the impact of cognitive training on driving among older adults with HF or other cardiovascular diseases.

\section{Acknowledgments}

The authors would like to thank Karlene Ball, PhD and the SKILL investigators. The authors would also like to acknowledge the entire ACTIVE study team.

Funding: This work was supported by the National Institutes of Health, National Institute on Aging [SKILL study 5 R37 AG05739-16; ACTIVE study U01 NR04507, U01 NR04508; U01 AG14260; U01 AG14282; U01 AG14263; U01 AG14289; U01 AG014276].

\section{References}

Ackerman M, Edwards JD, Ross LA, Ball KK, Lunsman M. Examination of cognitive and instrumental performance as indicators for driving cessation risk factors across 3 years. Gerontologist. 2008; 48:802-810. [PubMed: 19139253]

Almeida OP, Beer C, Lautenschlager NT, Arnolda L, Alfonso H, Flicker L. Two-year course of cognitive function and mood in adults with congestive heart failure and coronary artery disease: The heart-mind study. Int. Psychogeriatr. 2012; 24:38-47. [PubMed: 22093251]

Alosco ML, Spitznagel MB, Cleveland MJ, Gunstad J. Cognitive deficits are associated with poorer simulated driving in older adults with heart failure. BMC Geriatr. 2013; 13

Alosco ML, Spitznagel MB, Cohen R, Sweet LH, Colbert LH, Josephson R, Hughes J, Rosneck J, Gunstad J. Reduced cognitive function predicts functional decline in patients with heart failure over 12 months. Eur. J. Cardiovasc. Nurs. 2014; 13:304-310. [PubMed: 23754840] 
Alwerdt J, Edwards JD, Ponrathi A, Valdes E. Longitudinal differences in cognitive functioning among older adults with and without heart failure. J. Aging Health. 2013; 25:1358-1377. [PubMed: 24084526]

Ball KK, Edwards JD, Ross LA, McGwin G. Cognitive training decreases motor vehicle collision involvement of older drivers. J. Am. Geriatr. Soc. 2010; 58:2107-2113. [PubMed: 21054291]

Benjamin EJ, Blaha MJ, Chiuve SE, Cushman M, Das SR, Deo R, de Ferranti SD, Floyd J, Fornage M, Gillespie C, Isasi CR, Jiménez MC, Jordan LC, Judd SE, Lackland D, Lichtman JH, Lisabeth L, Liu S, Longenecker CT, Mackey RH, Matsushita K, Mozaffarian D, Mussolino ME, Nasir K, Neumar RW, Palaniappan L, Pandey DK, Thiagarajan RR, Reeves MJ, Ritchey M, Rodriguez CJ, Roth GA, Rosamond WD, Sasson C, Towfighi A, Tsao CW, Turner MB, Virani SS, Voeks JH, Willey JZ, Wilkins JT, Wu JHY, Alger HM, Wong SS, Muntner P. American Heart Association Statistics Committee, Stroke Statistics Subcommittee. Heart disease and stroke statistics-2017 update: A report from the American Heart Association. Circulation. 2017; 135:e146-e603. [PubMed: 28122885]

US Department of Health and Human Services. , editor. Centers for Medicare and Medicaid Services. Chronic conditions prevalence state/county table: Fee-for-service beneficiaries 65 years and over. 2015. Baltimore, MD: 2017.

Chihuri S, Mielenz TJ, DiMaggio CJ, Betz ME, DiGuiseppi C, Jones VC, Li G. Driving cessation and health outcomes in older adults. J. Am. Geriatr. Soc. 2016; 64:332-341. [PubMed: 26780879]

Edwards JD, Bart E, O'Connor ML, Cissell GM. Ten years down the road: Predictors of driving cessation. Gerontologist. 2010; 50:393-399. [PubMed: 19726733]

Edwards JD, Delahunt PB, Mahncke HW. Cognitive speed of processing training delays driving cessation. J. Gerontol. A Biol. Sci. Med. Sci. 2009a

Edwards JD, Lunsman M, Perkins M, Rebok GW, Roth DL. Driving cessation and health trajectories in older adults. J. Gerontol. A Biol. Sci. Med. Sci. 2009b; 64:1290-1295. [PubMed: 19675177]

Edwards JD, Myers C, Ross LA, Roenker DL, Cissell GM, McLaughlin AM, Ball KK. The longitudinal impact of cognitive speed of processing training on driving motility. Gerontologist. 2009c; 49:485-494. [PubMed: 19491362]

Edwards JD, Perkins M, Ross LA, Reynolds SL. Driving status and three-year mortality among community-dwelling older adults. J. Gerontol. A Biol. Sci. Med. Sci. 2009d; 64:300-3005. [PubMed: 19181711]

Edwards JD, Ross LA, Ackerman M, Small BJ, Ball KK, Bradley S, Dodson JE. Longitudinal predictors of driving cessation among older adults from the ACTIVE clinical trial. J. Gerontol. B Psychol. Sci. Soc. Sci. 2008; 63:P6-P12. [PubMed: 18332196]

Edwards JD, Ross LA, Wadley VG, Clay OJ, Crowe M, Roenker DL, Ball KK. The useful field of view test: Normative data for older adults. Arch. Clin. Neuropsychol. 2006; 21:275-286. [PubMed: 16704918]

Edwards JD, Vance DE, Wadley VG, Cissel GM, Roenker DL, Ball K. Reliability and validity of useful field of view test scores as administered by personal computer. J. Clin. Exp. Neuropsychol. 2005a; 27:529-543. [PubMed: 16019630]

Edwards JD, Wadley VG, Vance DE, Wooda K, Roenker DL, Ball K. The impact of speed of processing training on cognitive and everyday performance. Aging and Mental Health. 2005b; 9:262-271. [PubMed: 16019280]

Ellis ML, Edwards JD, Petersen L, Roker R, Athilingam P. Effects of cognitive speed of processing training among older adults with heart failure. J. Aging Health. 2014; 26:600-615. [PubMed: 24681975]

Emerson JL, Johnson AM, Dawson JD, Uc EY, Anderson SW, Rizzo M. Predictors of driving outcomes in advancing age. Psychol. Aging. 2012; 27:550-559. [PubMed: 22182364]

Folstein MF, Folstein SE, McHugh PR. "Mini-mental state": A practical method for grading the cognitive state of patients for the clinician. J. Psychiatr. Res. 1975; 12:189-198. [PubMed: 1202204]

Freeman EE, Gange SJ, Muñoz B, West SK. Driving status and risk of entry into long term care in older adults. Am. J. Public Health. 2006; 96:1254-1259. [PubMed: 16735633] 
Gure TR, Blaum CS, Giordani B, Koelling TM, Galecki A, Pressler SJ, Hummel SL, Langa KM. Prevalence of cognitive impairment in older adults with heart failure. J. Am. Geriatr. Soc. 2012; 60:1724-1729. [PubMed: 22882000]

Jobe JB, Smith DM, Ball K, Tennstedt SL, Marsiske M, Willis SL, Rebok GW, Morris JN, Helmers KF, Leveck MD, Kleinman K. ACTIVE: A cognitive intervention trial to promote independence in older adults. Control. Clin. Trials. 2001; 22:453-479. [PubMed: 11514044]

Kemp CD, Conte JV. The pathophysiology of heart failure. Cardiovasc. Pathol. 2012; 21:365-371. [PubMed: 22227365]

Leto L, Feola M. Cognitive impairment in heart failure patients. Journal of Geriatric Cardiology. 2014; 11:316-328. [PubMed: 25593581]

Lossnitzer N, Herzog W, Stork S, Wild B, Muller-Tasch T, Lehmkuhl E, Zugck C, Regitz-Zagrosek V, Pankuweit S, Maisch B, Ertl G, Gelbrich G, Angermann CE. Competence Network Heart Failure. Incidence rates and predictors of major and minor depression in patients with heart failure. Int. J. Cardiol. 2013; 167:502-507. [PubMed: 22341693]

Madvig MU, Mads E, Mads A, Charlotte A, Christian H, Christian T, Finn G, Lars K. Clinical characteristics and major comorbidities in heart failure patients more than 85 years of age compared with younger age groups. Eur. J. Heart Fail. 2011; 13:1216-1223. [PubMed: 21896536]

Marottoli RA, Mendes de Leon CF, Glass TA, Williams CS, Cooney LM, Berkman LF. Consequences of driving cessation: Decreased out-of-home activity levels. J. Gerontol. B Psychol. Sci. Soc. Sci. 2000; 55:S334-S340. [PubMed: 11078110]

Murad K, Goff DC, Morgan TM, Burke GL, Bartz TM, Kizer JR, Chaudhry SI, Gottdiener JS, Kitzman DW. Burden of comorbidities and functional and cognitive impairments in elderly patients at the intial diagnosis of heart failure and their impact on total mortality. The Cardiovascular Health Study. JACC: Heart Failure. 2015; 3:542-550. [PubMed: 26160370]

Owsley C, Stalvey B, Wells J, Sloane ME. Older drivers and cataract: Driving habits and crash risk. J. Gerontol. A Biol. Sci. Med. Sci. 1999; 54:M203-M211. [PubMed: 10219012]

Pressler SJ, Subramanian U, Kareken D, Perkins SM, Gradus-Pizlo I, Sauve MJ, Ding Y, Kim J, Sloan R, Jaynes H, Shaw RM. Cognitive deficits in chronic heart failure. Nurs. Res. 2010; 59:127-139. [PubMed: 20216015]

Roenker DL, Cissell GM, Ball KK, Wadley VG, Edwards JD. Speed-of-processing and driving simulator training result in improved driving performance. Hum. Factors. 2003; 45:218-233. [PubMed: 14529195]

Sims RV, Muib M, McGwin G, Zhang Y, Ahmed MI, Desai RV, Aban IB, Swayer P, Anker S, Ahmed A. Heart failure is a risk factor for incident driving cessation among community-dwelling older adults: Findings from a prospective population study. J. Card. Fail. 2011; 17:1035-1040. [PubMed: 22123368]

Steinhagen-Thiessen, E., Borchelt, M. Morbidity, medication, and functional limitations in very old age. In: Baltes, PB., Mayer, KU., editors. The Berlin Aging Study: Aging from 70 to 100. Cambridge University Press; New York: 1999.

Tager IB, Swanson A, Satariano WA. Reliability of physical performance and self-reported functional measures in an older population. The journals of gerontology. Series A, Biological sciences and medical sciences. 1998; 53:M295-M300.

Tombaugh TN, McIntyre NJ. The mini-mental state examination: A comprehensive review. J. Am. Geriatr. Soc. 1992; 40:922-935. [PubMed: 1512391]

van Deursen VM, Urso R, Laroche C, Damman K, Dahlström U, Tavazzi L, Maggioni AP, Voors AA. Co-morbidities in patients with heart failure: An analysis of the European Heart Failure Pilot Survey. Eur. J. Heart Fail. 2014; 16:103-111. [PubMed: 24453099]

Wechsler, D. Wechsler Adult Intelligence Scale-Revised. Psychological Corporation; San Antonio, TX: 1981.

Wood KM, Edwards JD, Clay OJ, Wadley VG, Roenker DL, Ball KK. Sensory and cognitive factors influencing functional ability in older adults. Gerontology. 2005; 51:131-141. [PubMed: $15711081]$ 


\section{Highlights}

- Heart failure was an initial predictor of driving cessation.

- Heart failure was not a predictor of driving cessation after considering cognitive function.

- The ramifications of cognitive decline in heart failure patients should be considered. 


\section{Table 1}

Summary Statistics for Demographic and Inclusion Variables of Analytic Sample by Heart Failure Status

\begin{tabular}{lcccc}
\hline Measure & \multicolumn{2}{c}{$\begin{array}{c}\text { Heart Failure } \\
(\boldsymbol{n}=\mathbf{2 9})\end{array}$} & \multicolumn{2}{c}{$\begin{array}{c}\text { No Heart Failure } \\
(\boldsymbol{n}=\mathbf{8 2 1})\end{array}$} \\
& $\boldsymbol{M}(\boldsymbol{n})$ & $\boldsymbol{S D}(\boldsymbol{\%})$ & $\boldsymbol{M}(\boldsymbol{n})$ & $\boldsymbol{S D}(\boldsymbol{\%})$ \\
\hline Demographics & & & & \\
Age (years) & 74.72 & 5.48 & 72.76 & 5.36 \\
Sex (female) & $(18)$ & $(62.10)$ & $(521)$ & $(63.50)$ \\
Race (Caucasian) & $(24)$ & $(82.80)$ & $(695)$ & $(84.70)$ \\
Education (years) & 13.59 & 2.26 & 14.03 & 2.67 \\
Mini Mental State Exam & 27.66 & 1.80 & 28.04 & 1.74 \\
Cognition & & & & \\
Useful Field of View ${ }^{*}$ & 1064.14 & 251.80 & 840.47 & 261.18 \\
Digit Symbol Substitution * & 36.31 & 10.68 & 42.19 & 10.31 \\
Sensory Function & & & & \\
Far Visual Acuity & 70.45 & 13.43 & 74.00 & 11.03 \\
Physical Function & & & & \\
Turn 360* & 7.76 & 1.87 & 6.74 & 1.65 \\
Driving Exposure & & & & \\
Days Driven Per Week & 5.62 & 1.45 & 5.76 & 1.63 \\
Stroke (Yes) * & $(5)$ & $(17.24)$ & $(51)$ & $(6.21)$ \\
\hline & & & &
\end{tabular}

Note. For Turn 360 and UFOV tests, lower scores indicate better performance;

* significant baseline differences by HF as indicated by $t$ tests or $\chi^{2}(p<.05)$. 


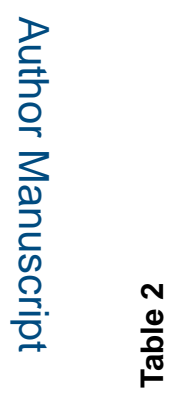

론

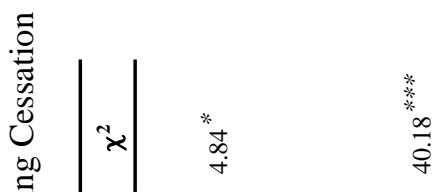

吾

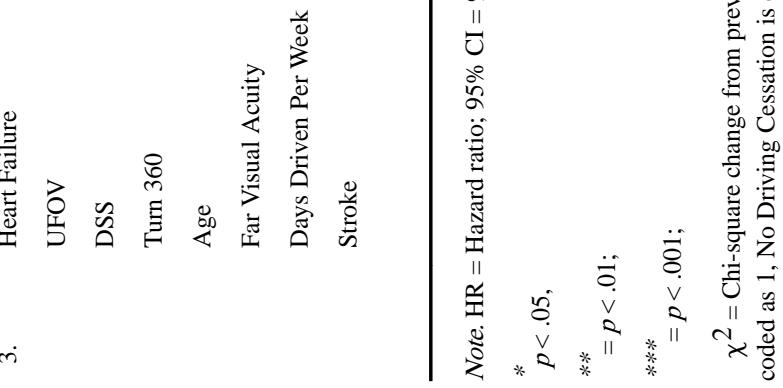

